\title{
EDITORIAL
}

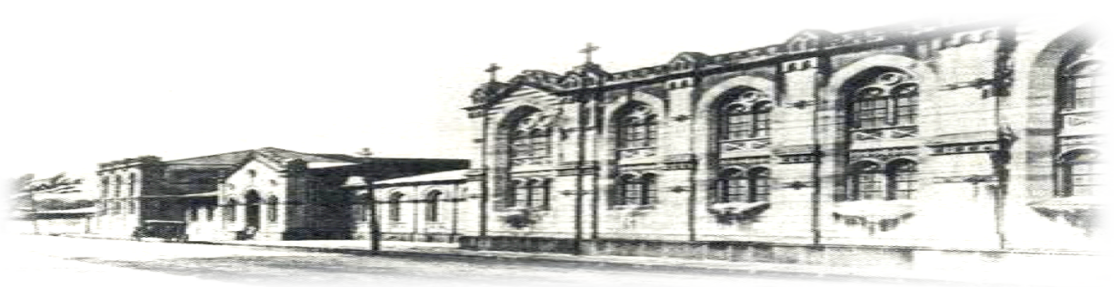

Haspital San quan de Dias. San Jasé, Casta Rica. Fundada en 1845

\section{Presentación del URL de la Revista Clínica de la Escuela de Medicina UCR-HSJD ante la comunidad médica nacional.}

$\begin{array}{ll}\text { Recibido: } & 12 / 06 / 2012 \\ \text { Aceptado: } & 13 / 06 / 2012\end{array}$

Ibrahim Barguil Meza 1

\footnotetext{
${ }^{1}$ Especialista en Medicina Interna. Jefe del Servicio de Medicina 1 HSJD. Profesor Interino Licenciado de la Cátedra de Medicina Interna, UCR-HSJD. Profesor del posgrado de Medicina Interna UCRCENDEISSS. Correo electrónico: ibarguil@ccss.sa.cr
}

Gracias a la ayuda incondicional de la Escuela de Medicina de la UCR, en la persona de su Director, el Dr. Ricardo Boza Corderro y a través del invaluable aporte del Ingeniero en Sistemas Warner Quesada, en este mes de junio, tenemos el agrado de presentar ante la comunidad médica nacional, el URL propio de nuestra revista, con lo que tendremos una página web independiente, de acceso gratuito y sin patrocinio externo.

En esta página tendremos varias secciones de interés: en la página de inicio, se mostrará el número de la revista que corresponde a la publicación del mes en curso (con sus secciones usuales). Por otro lado, en el menú vertical, hemos trabajado en el desarrollo de enlaces de interés, y que sean de ayuda para los médicos que accesen la página, siempre con el deseo de brindar oportunidades para favorecer la actualización médica continua.
Dentro de los enlaces de interés tenemos: alertas de farmacia, donde publicamos los boletines del Programa de Farmacovigilancia del Centro de Información de Medicamentos, del Servicio de Farmacia de nuestro hospital. En esta parte, también hay un enlace con el Programa Internacional de Famacovigilancia, auspiciado por la Organización Mundial de la Salud.

En el apartado de Literatura Recomendada, se publica los boletines desarrollados por la Biblioteca Nacional de Salud y Seguridad Social (BINASSS), que son elaborados por médicos especialistas en los campos respectivos y cuyo contenido puede ser solicitado a través de la dirección de correo habilidada para tal fin, de forma totalmente gratuita.

Finalmente, contamos con enlaces directos con BINASSS, el Instituto Clodomiro Picado y el 
INCIENSA, donde es posible encontrar gran candtidad de información médica de interés.

Aprovecho este espacio para agradecer a todos los colaboradores que han hecho posible la realización de este proyecto, que esperamos sea de utilidad para el gremio. 